\title{
Evidências Empíricas da Influência da Família, Mídia, Escola e Pares nos Antecedentes e no Comportamento de Separação de Materiais para a Reciclagem
}

\author{
Empirical Evidence of the Influence of Family, Media, School and Peers in the \\ Separation of Materials for Recycling
}

Carolina Fabris * Mestre em Administração pela UFPR, Curitiba/PR, Brasil.

Pedro José Steiner Neto Doutor em Administração pela USP. Professor da UFPR, Curitiba/PR, Brasil.

Ana Maria Machado Toaldo Doutora em Administração pela UFRGS. Professora do PPGADM/UFPR, Curitiba/PR, Brasil.

* Endereço: Carolina Fabris

Rua Brasílio Itiberê, 4028, apto. 20, Água Verde, 80240-060, Curitiba/PR. E-mail: carolina.fabris@gmail.com

Copyright (C) 2010 RAC. Todos os direitos, inclusive de tradução, são reservados. É permitido citar parte de artigos sem autorização prévia desde que seja identificada a fonte. 


\title{
RESUMO
}

Este artigo analisa a influência dos agentes de socialização - no caso, a família, a escola, a mídia e os pares - no conhecimento, no sentimento e no comportamento de separação de materiais para a reciclagem de jovens universitários. Para isto, a revisão teórica faz uma ligação entre a última etapa do comportamento do consumidor, que engloba a separação de materiais para a reciclagem, e os agentes de socialização que já foram estudados como influências em outros tipos de comportamentos. Um modelo e sete hipóteses foram propostos pelos autores. A pesquisa foi dividida em duas etapas. A primeira, qualitativa e exploratória. A segunda, quantitativa e descritiva, realizada com 351 universitários. As análises quantitativas utilizaram modelagem de equações estruturais para verificar o modelo proposto. Os resultados mostram que os quatro agentes influenciam de maneira direta ou indireta o comportamento dos jovens na separação de materiais para a reciclagem. $\mathrm{O}$ comportamento é influenciado diretamente pelo contato pessoal: família e pares. Porém, de maneira indireta, a escola, a mídia e os pares agem nos sentimentos, que são considerados antecedentes do comportamento.

Palavras-chave: processo decisório do consumidor; agentes de socialização; comportamento de separação de materiais para a reciclagem.

\begin{abstract}
This article analyzes the influence of family, school, media and peers on knowledge, in the sense of separation and the behavior of separation of materials for recycling by university students. To this end, the review makes a theoretical connection between the last stage of consumer behavior, which includes the separation of materials for recycling, and the agents of socialization that have been studied as influences on other types of behavior. A model and seven hypotheses were proposed by the authors. The research was divided into two stages. The first is characterized as a qualitative exploratory stage. The second, quantitative stage, was conducted with 351 university students. The quantitative analysis used the structural equation modeling to verify the proposed model. The results show that the four agents influence behavior during separation of materials for recycling either directly or indirectly. The behavior is influenced directly by personal contact (family and peers). But indirectly, the school, the media and peers impinge on feelings, serving as an antecedent of behavior.
\end{abstract}

Key words: decision making of consumers; agents of socialization; recycling behavior. 


\section{INTRODUÇÃO}

As pessoas se deparam diariamente com situações em que tomar decisões se faz necessário. Quando se trata do consumo, tais decisões podem envolver desde a opção de compra de determinado produto, em qual local comprar, qual a forma de pagamento, se consomem ou não, em qual momento, de qual maneira, até questões que abarcam o pós-consumo, como o que fazer com os produtos ou embalagens (Engel, Blackwell, \& Miniard, 2000).

Dentro desta perspectiva, diversos autores da área de comportamento do consumidor já propuseram modelos que auxiliam a visualização e representação desse processo (Engel et al., 2000; Solomon, 2002); Engel et al. (2000) destaca a última etapa, que envolve optar pelo descarte sumário do produto, pelo remarketing ou pela reciclagem.

Este último processo, a reciclagem, vem ganhando destaque após o aumento da preocupação com a preservação do meio ambiente, utilização da energia, diminuição de $\mathrm{CO}^{2}$, além de novas leis (Engel et al., 2000, Johansson \& Luttropp, 2009, Luttropp \& Johansson, 2010). O lixo sempre esteve presente na sociedade e a maneira que a população adota para livrar-se dele já passou por diversos métodos, tendo a preocupação com o meio ambiente pressionado muitas dessas mudanças. Com esta evolução, a reciclagem passou a ser considerada uma das abordagens para o problema do lixo (Shrum, Lowrey, \& Mccarty, 1994). Embora não a única, conforme as prioridades em relação à gestão de resíduos sólidos, publicadas pelos países da OCDE em 1975 (Demajorovic, 1995).

Diante destas afirmativas, surgem questionamentos em relação à maneira com que os jovens, imersos em uma sociedade de consumo, ao mesmo tempo que se deparam com diversos problemas ambientais, lidam com a última etapa do consumo, mais especificamente, a separação de materiais para a reciclagem.

Este artigo parte da premissa de que as ações em busca de conscientização e aumento das práticas de separação de materiais para a reciclagem terão pouco progresso até que se conheçam as raízes que as causam. Desta maneira, adotando como enfoque tanto as características pessoais que cada jovem pode apresentar e interferir neste processo, quanto um enfoque que busca nas relações do jovem com seu contexto social explicações para determinado comportamento, o objetivo deste artigo é analisar a influência da família, da escola, da mídia e dos pares no conhecimento, no sentimento e no comportamento de jovens universitários na questão da separação de materiais para a reciclagem.

Estas análises contribuem para maior entendimento de um dos procedimentos possíveis na última etapa do comportamento do consumidor: a reciclagem. Este tema já foi abordado internacionalmente por diversas perspectivas; como exemplo os estudos de Ekvall (1999), Carrus, Passafaro e Bonnes (2008), Corral-Verdugo (1997), McDonald e Ball (1998), Seacat e Northrup (in press), Schultz, Oskamo e Manieri (1995), Suttibak e Nitivattananon (2008), Sidique, Lupi e Joshi (2010) e Werner e Makela (1998). Porém, são poucos os estudos que a relacionam com a família, mídia, pares e escola (Gronhoj \& Thogersen, 2009; Lyons \& Breakwell, 1994; Manieri, Barnett, Valdero, Unipan, \& Oskamp, 1997; Werner et al., 1995).

No âmbito nacional e, especificamente, na área de Marketing e Comportamento do Consumidor, a reciclagem foi abordada mais como uma dimensão do consumidor ambientalmente favorável (Instituto Akatu, 2004; Lages \& Vargas, 2002; Romeiro, 2006) e não como comportamento específico dentro do processo decisório do consumidor. Assim, pesquisas que auxiliam no entendimento de como se dão essas escolhas, bem como suas influências, perante a visão do consumidor, contribuem para esta área.

De acordo com Valle, Rebelo, Reis e Menezes (2005), os antecedentes do comportamento de reciclagem oferecem grandes oportunidades de pesquisa; além disso, é uma área que se encontra em fase exploratória, na qual diversos resultados contraditórios estão presentes (Berger, 1997). Desta 
maneira, este artigo procura fornecer mais discussões sobre esses antecedentes, o que, em consequência, auxilia no melhor entendimento desse processo.

Os resultados contribuem de maneira prática com três setores: meio ambiente, governo e empresas. Os resultados podem auxiliar a divulgar e influenciar este tipo de prática perante este público, colaborando para que diminua a quantidade de lixo e se auxilie a proteção do meio ambiente. Pode auxiliar o governo a realizar campanhas de reciclagem mais efetivas, além de repensar políticas públicas que envolvem os agentes de socialização pesquisados. Ainda, pode contribuir para um setor que movimenta oito bilhões de reais por ano (Compromisso Empresarial para a Reciclagem [Cempre], 2008). Os resultados também auxiliam as empresas que já estão preocupadas com o marketing social e o marketing verde.

\section{FUNDAMENTAÇÃO TEÓRICA}

A fundamentação teórica busca abordar cada variável escolhida para este estudo. Primeiramente apresenta seu conceito e, na sequência, relaciona a variável com o comportamento de separação de materiais para a reciclagem.

\section{Comportamento na Separação de Materiais para a Reciclagem}

Demajorovic (1995) analisou as mudanças da política de gestão de resíduos sólidos nos países da Organização para a Cooperação e Desenvolvimento Econômico [OCDE], durante o final da década de 60 até os anos 90. O autor identificou três fases nesse período: (1) Fase focada apenas em garantir a disposição dos resíduos; (2) Fase em que mudanças no tratamento de resíduos foram evidenciadas, tais como redução da produção de resíduos, reciclagem do material, incineração com aproveitamento da energia e disposição em aterros controlados; (3) Fase focada na redução de resíduos, a prioridade é que eles não sejam gerados e que sejam reutilizados.

A reciclagem já foi alvo de críticas no final da década de 80, quando foi discutido o consumo de energia e resíduos gerados (Demajorovic, 1995). Porém, entre as soluções para a gestão de resíduos sólidos, a reciclagem é a que mais se relaciona com a última etapa do processo de consumo, alvo deste estudo.

A reciclagem ainda ganha maior destaque na gestão de resíduos sólidos, quando discutida em países em desenvolvimento, como o Brasil. Este processo é abordado por Binder e Mosler (2007). Os autores destacaram as diferenças de países desenvolvidos e subdesenvolvidos em relação a este tema. Nos países industrializados, aspectos econômicos parecem impactar mais as taxas de reciclagem. Já nos países em desenvolvimento, o governo não apresenta papel muito relevante em prover boa infraestrutura para a reciclagem nem nos subsídios. O setor informal é que passa a ter papel central neste processo (Binder \& Mosler, 2007).

Na literatura sobre o comportamento do consumidor (Engel et al., 2000), a reciclagem, conforme já foi apresentada, insere-se como a última etapa do processo decisório do consumidor. $\mathrm{O}$ estudo da relação entre redução de lixo e outras formas de gerenciamento de lixo sólido são relativamente recentes e, muitas vezes, vem colocadas perspectiva do consumidor ambientalmente favorável. Porém, destaca-se que, embora a responsabilidade ambiental e reciclagem sejam comportamentos de gerenciamento de lixo, elas podem apresentar diferentes antecedentes (Ebreo, Hershey, \& Vining, 1999); em consequência, merecem ser estudadas de maneira separada.

Heckler (1994) afirma que a pesquisa sobre comportamento de separação de materiais para a reciclagem vem sendo conduzida desde a metade da década de 1970. Entre os estudos com uma perspectiva mais qualitativa, foi investigado o significado do lixo para os consumidores do Brasil e do Reino Unido (Bekin, Carrigan, \& Szmigin, 2007). Dentre as considerações encontradas, foi 
identificado que os participantes dos dois países consideram papéis similares para o lixo, o relacionando com abundância e conveniência. O lixo é percebido por essas duas culturas nos estágios de compra e consumo.

Já em perspectiva mais quantitativa, grande quantidade de estudos focou na natureza psicológica da reciclagem. Estes estudos podem ser divididos em categorias, como estas: (a) atitudes e crenças; (b) valores pessoais; e (c) traços (Shrum et al., 1994). Outros pesquisadores têm abordado variáveis demográficas, conhecimento e sentimento de preocupação ambiental.

Todavia as evidências apontadas na literatura mostram que é uma área que se encontra em fase exploratória, vista a quantidade de variáveis observadas e os resultados, muitas vezes conflitantes.

Como panorama geral, variáveis demográficas se mostraram fracos antecedentes do comportamento de reciclagem e, consequentemente, pouco indicadas como variáveis de segmentação. Do mesmo modo, a pesquisa sobre atitudes apresenta-se um pouco confusa, mas sugere um nível de especificidade para mensuração importante. Por outro lado, as pesquisas que abordaram conceitos mais abstratos, como valores, valores culturais e traços, indicam maneiras para explorar uma comunicação mais persuasiva que pode ser designada para atrair não-recicladores (Shrum et al., 1994).

\section{Conhecimento e Comportamento na Separação de Materiais para a Reciclagem}

O conhecimento é definido por Engel et al. (2000) como a informação armazenada na memória. Quando se trata do consumidor, essas informações que operam no mercado são chamadas de conhecimento do consumidor; podem ser em relação às características dos produtos e serviços, os locais onde podem ser comprados e a maneira de usá-los.

Uma distinção feita para facilitar o entendimento e a pesquisa do conhecimento divide esse conceito em duas dimensões: (1) conhecimento objetivo e (2) conhecimento subjetivo. A diferença conceitual entre esses dois tipos é que o conhecimento objetivo se refere apenas ao que o indivíduo realmente sabe (Brucks, 1985; Engel et al., 2000), à informação exata sobre a classe de produto (Park, Mothersbaug, \& Feick, 1994). O conhecimento subjetivo inclui um grau individual de confiança (Brucks, 1985) e se relaciona com a percepção dos consumidores sobre o nível de conhecimento que acreditam ter, o quanto e o que eles acham que sabem sobre a classe de produtos (Duhan, Johnson, Wilcox, \& Harrell, 1997; Park et al., 1994).

Quando se trata do consumidor, o conhecimento merece atenção, devido às discussões sobre o impacto que ele tem no processo de decisão. Bettman e Park (1980) afirmam que a presença ou ausência de conhecimento pode afetar os processos heurísticos que os consumidores desenvolvem, bem como os tipos de informação que utilizam. Brucks (1985), por sua vez, encontrou relação positiva entre o conhecimento prévio, a habilidade de processar novas informações e a eficiência das informações processadas. Outra relevância é o fato de que o conhecimento do consumidor em relação a determinado produto pode ter significativo impacto na atitude, julgamento e escolha (Alba \& Hutchison, 1987).

Algumas evidências foram apontadas na relação conhecimento e meio ambiente, tais como as relacionadas por Linn, Vinning e Feeles (1994). Neste estudo, os resultados mostraram que os respondentes podem dar exemplos de produtos passíveis de reciclagem e quanto maior essa familiaridade, maior a participação em programas de reciclagem. Simmons e Widmar (1990 como citado em Daneshvary, Daneshvary, \& Schwer, 1998) apontam que os indivíduos com mais conhecimento do que separar e como separar os materiais para reciclar eram mais propensos de agir do que aqueles com menos conhecimento.

Luttropp e Johansson (2010) defenderam a importância da informação para tornar o processo de reciclagem mais eficiente e que estas informações deveriam ser fixadas no produto de maneira que consumidor já se conscientize da fase final deste. 


\section{Sentimentos e o Comportamento de Separação de Materiais para a Reciclagem}

As respostas afetivas representam os sentimentos e emoções que são trazidos à tona por um estímulo, durante o processo de compra e consumo. Algumas pesquisas mostraram a importância de respostas afetivas durante o estágio de aceitação do processamento de informação. Por exemplo, um estudo reporta que tanto respostas cognitivas quanto as afetivas foram úteis na previsão de atitudes formadas depois da exposição ao anúncio (Engel et al., 2000).

As respostas afetivas estudadas acabam sendo os sentimentos, emoções e o humor. Os sentimentos merecem aqui especial destaque, porque representam, segundo Frijda, Mesquita, Sonnemans e Goozen (1991), disposições de responder emocionalmente a um objeto definido; é uma disposição que transforma eventos simples em emocionalmente carregados. Quanto à duração do afeto, pode-se dizer que os sentimentos são relativamente duradouros (Frijda et al., 1991).

Muitos sentimentos são adquiridos pelo exemplo social, por escutar um discurso carregado emocionalmente, por esquemas presentes em livros e outras mídias, e pelo testemunho de comportamentos emocionais dos outros (Frijda, Manstead, \& Bem, 2000). Os sentimentos podem resultar da relevância de pertencer a um grupo. Também podem ser respostas para consequências sociais esperadas e podem surgir porque são eventos ou questões preocupantes para o indivíduo (Frijda et al., 2000). Estes dois últimos pontos estão relacionados com o tema deste estudo.

Os sentimentos são pouco citados nos estudos de reciclagem e muitas vezes não aparecem com esta denominação. Um exemplo são as recompensas intrínsecas que Ebreo et al. (1999) cita dos estudos de Young em relação à reciclagem: parcimônia, autos-suficiência e participação, além da satisfação que os pesquisados afirmaram sentir por estarem participando de atividades de conservação (Ebreo et al., 1999). Fato semelhante é mostrado por Hopper e Nielsen (1991), que concluíram: os mais propensos a agir são os que acreditam que suas ações podem fazer a diferença para o problema do lixo. Outro estudo neste âmbito foi desenvolvido por Carrus, Passafaro e Bonnes (2008). Os autores partiram da premissa de que emoções anteriores e comportamentos passados podem ser significantes no direcionamento dos desejos individuais e intenções de agirem a favor do meio ambiente. Para tanto, avaliaram a reciclagem e a utilização de transporte público. Os resultados evidenciaram que a antecipação de emoções negativas pode ser antecedente na orientação individual de intenção de comportamento ambiental.

\section{Agentes de Socialização e o Comportamento de Separação de Materiais para a Reciclagem}

Engel et al. (2000) definem o processo de socialização do consumidor como a aquisição de cognições, atitudes e comportamentos relacionados ao consumo. Moschis e Churchill (1978), vistos como referências nesta área, definem esse processo como o meio pelo qual as pessoas jovens desenvolvem habilidades relacionadas ao consumo, conhecimento e atitudes. Porém, embora os estudos iniciais tivessem como foco apenas os jovens, atualmente esse processo é reconhecido como vitalício (Engel et al., 2000).

Diante da complexidade desse processo, diversas abordagens surgem como forma de explicá-lo, uma das mais populares é o modelo de aprendizagem social, o qual geralmente vê a socialização como resultado de forças do ambiente aplicadas ao indivíduo (Busch, Smith, \& Martin, 1999). O processo de aprendizagem social não ocorre no vácuo, mas no contexto social. Assim, os agentes sociais são vistos como integrantes deste, podendo ser uma pessoa ou organização, tais como a família, pais, mídia de massa, entre outros (Churchill \& Moschis, 1979; Moschis \& Churchill, 1978; Moschis \& Moore, $1978,1979,1982)$.

Desse modo, a socialização é fruto das interações com os agentes que participam desse processo de aprendizagem do indivíduo, por meio de modelagem (imitação de um comportamento do que ensina), 
de reforço (positivo e negativo) e de interação social; esta última pode incluir a modelagem e reforço (Moschis \& Churchill, 1978; Moschis \& Moore, 1978, 1979, 1982).

Os resultados apontados neste processo são as questões aprendidas, cuja aplicação serve ao entendimento das influências em diversos tipos de comportamentos e atitudes, tais como as seguintes: exatidão do preço, lembrança do slogan, especificação de marca, comportamento de consumo, conhecimento legal, concepção do papel do consumidor, atitude perante o preço, materialismo, busca de informações, motivações, entre outros (Churchill \& Moschis, 1979; J. Moore, Raymond, Mittelstaedt, \& Tanner, 2002; Moschis \& Churchill, 1978; Moschis \& Moore, 1978, 1979, 1982; R. Moore \& Stephens, 1975).

Para este estudo, diante do referencial apresentado até o momento, os quatro agentes escolhidos foram: (1) família, (2) escola, (3) mídia e (4) pares e são detalhados nos parágrafos subsequentes. A escolha desses agentes teve como base os estudos citados neste item, além de autores como Engel et al. (2000), Newcombe (1999) e a afirmação de Werner et al. (1995) sobre a importância da pressão da família, dos vizinhos e da escola na mudança de atitude e comportamento em relação à reciclagem.

Em relação à família (1), as relações entre gerações são enfatizadas; elas podem ser fatores explicativos de compartilhamento de preferências específicas, como marcas, até questões mais abstratas, como atitudes e valores (Moore-Shay \& Berchmans 1996), conhecimento e habilidades (John, 1999). A criança pode aprender o comportamento do consumidor, porque seus pais diretamente lhe ensinam ou porque aprende da observação do comportamento deles (Cotte \& Wood, 2004). Argumenta-se que as crianças se espelham em seus pais, sendo eles os primeiros meios de transmissão cultural na sociedade. Assim, as questões aprendidas no contexto familiar impactam também no comportamento do indivíduo enquanto adulto (Moore-Shay \& Berchmans, 1996).

A ordem de nascimento também apresenta impacto na necessidade de diferenciação do filho mais velho em relação aos filhos mais novos, pois muitas vezes os encaram como ameaça no relacionamento com seus pais, com os quais apresentavam exclusividade de afeição. Já os filhos mais novos são mais suscetíveis de ressentimento de seus irmãos mais velhos, que apresentam um ar mais dominante, tendendo a buscar valores em seus pares. Assim, os primogênitos são vistos com modos de consumo mais próximos de seus pais, enquanto a comunicação sobre consumo com os pares é esperada com mais frequência nos que nascem depois (Churchill \& Moschis, 1979).

Desta maneira, os irmãos também podem ser uma fonte de influência de atitude e comportamento. Neste artigo os irmãos também foram considerados na mensuração do construto influência da família. Porém, nem todos os entrevistados apresentavam irmãos, fato que provocou um número de missing values muito elevado (16\%). Desta maneira, as perguntas referentes aos irmãos foram desconsideradas das análises.

Nos estudos sobre reciclagem, Gronhoj e Thogersen (2009) examinaram as similaridades entre os valores, atitudes e comportamentos de pais e filhos na compra de produtos ambientalmente favoráveis, uso de eletricidade e maneira como lidam com o lixo. Os resultados apontaram relações positivas entre os valores de pais e filhos. Porém, as correlações mais fortes foram para atitude e comportamento.

As escolas (2) são vistas como meio que pode contribuir para a construção da identidade dos adolescentes e também para ensinar-lhes atividades de cidadania. Assim, podem impactar no comportamento de consumo dos jovens (Ahava \& Palojoki, 2004). Especificamente, a questão do consumo pode ser vista como parte da educação e socialização das crianças e jovens e com papel importante do desenvolvimento da identidade e autoimagem (Benn, 2004). Porém, em relação à educação sobre o consumo, é visto que tal tema aprendido na escola será mais relevante no futuro do adolescente e não no momento em que é ensinado (Ahava \& Palojoki, 2004).

O terceiro agente de socialização estudado, a mídia de massa (3) pode ser apontada como uma das maneiras indiretas em que os indivíduos adquirem conhecimento para tomar decisões e realizar julgamentos. Esse meio pode ser fonte de informação e também influenciador do processo de decisão, tanto por meio das propagandas, quanto dos programas (Shrum, O'Guinn, Semenik, \& Faber, 1991). 
Devido à exposição dos jovens às diversas propagandas, por exemplo, eles podem desenvolver orientações favoráveis em relação à determinada marca (Moschis \& Moore, 1979). Além disso, as propagandas podem ser vistas como base para as interações sociais (Ritson \& Elliot, 1999). Heckler (1994) mostrou estudos que identificaram que esta forma de comunicação, além da interpessoal, pode ser efetiva no aumento do comportamento de reciclagem. Dessa forma, a mídia de massa não é vista apenas como meio de informação do produto, mas também como agente de socialização que pode modelar o comportamento e atitude de consumo dos indivíduos (R. Moore \& Stephens, 1975).

O estudo de Manieri et al. (1997) encontrou como fonte mais importante de conhecimento sobre meio ambiente os jornais e revistas, seguidos da TV e notícias de rádio. Outro estudo nesta área foi feito por Lyons e Breakwell (1994), no qual se demonstrou que a variável exposição a programas científicos de TV é um dos diferenciais dos jovens mais conscientes sobre o meio ambiente.

Por fim, em relação aos pares (4), embora a influência dos pais esteja presente, quando o indivíduo passa a ter contato, com maior frequência, com outras pessoas, estas também podem tornar-se fator relevante no seu processo de socialização como consumidor. Algumas habilidades de consumo seriam adquiridas dos pares, como, por exemplo, um adolescente pode aprender marcas boas e más de determinado produto da boca de seus amigos (R. Moore \& Stephens, 1975). A maneira como esse processo ocorre se mostra mais forte, quando a comunicação no ambiente familiar não é estável e forte (John, 1999). Além disso, ocorre da observação dos adolescentes nas atividades relacionadas ao consumo de seus amigos, para tomarem decisões no mercado (J. Moore et al., 2002).

Uma evidência sobre a influência dos pares em comportamentos relacionados com meio ambiente foi demonstrada por Werner, Sansone e Brown (2008) sobre a substituição de produtos tóxicos por não tóxicos. Os resultados mostraram que os grupos representam um meio de persuasão efetivo, embora atuem de maneira diferente: as mulheres são mais influencias pela opinião de seus pares do que os homens.

Foram poucas as abordagens do contexto social como fator de importância no comportamento de reciclagem. Até mesmo esta afirmação se estende para o comportamento ambientalmente favorável do consumidor como um todo. Kurz, Linden e Sheehy (2007) destacam o trabalho de Vining e Ebreo (2002), que aponta os poucos estudos que incluem as diferenças de contexto, como as vizinhanças e a comunidade na qual os indivíduos residem (Kurz et al., 2007). Assim, visualizou-se a importância das variáveis escolhidas para este estudo e a relação que estas podem apresentar.

\section{MÉTODO DE PESQUISA}

Esta seção descreve o modelo proposto e suas hipóteses e apresenta as características da etapa qualitativa e quantitativa realizadas. Tendo em vista os aspectos abordados na revisão da literatura com foco no contexto de reciclagem, sete hipóteses foram formuladas, sendo as quatro primeiras divididas em quatro sub-hipóteses. A Figura 1 permite visualizar o modelo proposto para o estudo, as variáveis envolvidas e suas relações, onde se apresenta a influência dos agentes de socialização no comportamento de separação de materiais para a reciclagem. As hipóteses estão detalhadas na Tabela 1. 


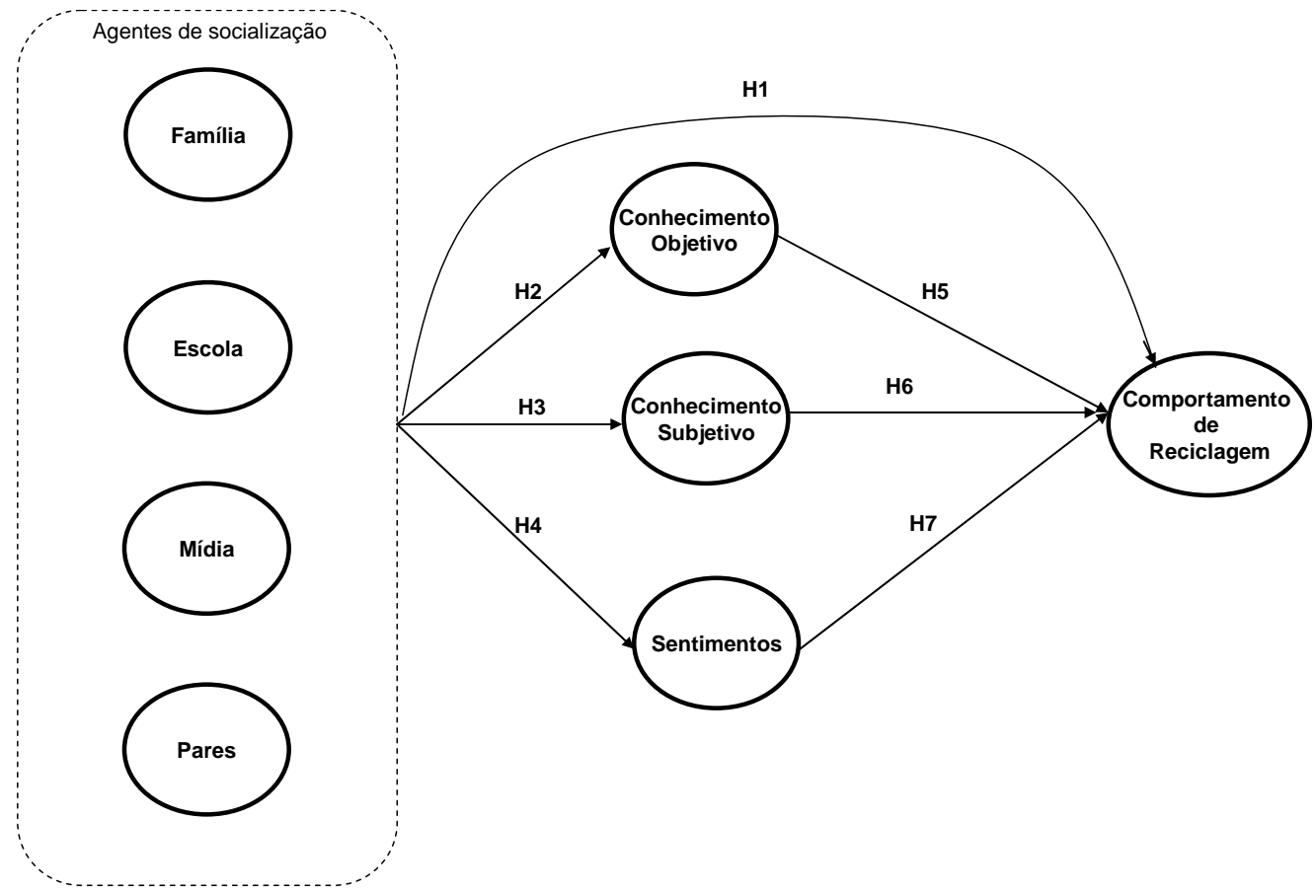

Figura 1. Modelo Conceitual Proposto para o Estudo.

Fonte: elaborado pelos autores.

Tabela 1

\section{Hipóteses de Pesquisa}

\section{Hipótese}

H1: Os agentes sociais afetam positivamente $o$ comportamento de separação de materiais para a reciclagem.

$\mathrm{H} 2$ : Os agentes sociais afetam positivamente $\mathrm{o}$ conhecimento objetivo sobre a separação de materiais para a reciclagem.

H3: Os agentes sociais afetam positivamente 0 conhecimento subjetivo sobre a separação de materiais para a reciclagem.

\section{Sub-hipótese}

H1a: A família afeta positivamente o comportamento de separação de materiais para a reciclagem.

H1b: A escola afeta positivamente o comportamento de separação de materiais para a reciclagem.

H1c: A mídia afeta positivamente o comportamento de separação de materiais para a reciclagem.

H1d: Os pares afetam positivamente o comportamento de separação de materiais para a reciclagem.

H2a: A família afeta positivamente o conhecimento objetivo sobre separação de materiais para a reciclagem.

H2b: A escola afeta positivamente o conhecimento objetivo sobre a separação de materiais para a reciclagem.

H2c: A mídia afeta positivamente o conhecimento objetivo sobre a separação de materiais para a reciclagem.

H2d: Os pares afetam positivamente o conhecimento objetivo sobre a separação de materiais para a reciclagem.

H3a: A família afeta positivamente o conhecimento subjetivo sobre a separação de materiais para a reciclagem.

H3b: A escola afeta positivamente o conhecimento subjetivo sobre a separação de materiais para a reciclagem.

H3c: A mídia afeta positivamente o conhecimento subjetivo sobre a separação de materiais para a reciclagem.

H3d: Os pares afetam positivamente o conhecimento subjetivo sobre a separação de materiais para a reciclagem. 


\section{Tabela 1 (continuação)}

\begin{tabular}{cl}
\hline Hipótese & \multicolumn{1}{c}{ Sub-hipótese } \\
\hline $\begin{array}{c}\text { H4: Os agentes sociais } \\
\text { afetam positivamente o } \\
\text { sentimento sobre separação } \\
\text { de materiais para a } \\
\text { reciclagem. }\end{array}$ & $\begin{array}{l}\text { H4a: A família afeta positivamente o sentimento sobre a separação de materiais para a } \\
\text { reciclagem. }\end{array}$ \\
$\begin{array}{l}\text { H4b: A escola afeta positivamente o sentimento sobre separação de materiais para a } \\
\text { reciclagem. } \\
\text { H4c: A mídia afeta positivamente o sentimento sobre separação de materiais para a } \\
\text { reciclagem. }\end{array}$ \\
$\begin{array}{l}\text { H4d: Os pares afetam positivamente o sentimento sobre separação de materiais para a } \\
\text { reciclagem. }\end{array}$ \\
H5: O conhecimento objetivo afeta positivamente o comportamento de separação de materiais para a reciclagem. \\
H6: O conhecimento subjetivo afeta positivamente o comportamento de separação de materiais para a reciclagem. \\
H7: O sentimento afeta positivamente o comportamento de separação de materiais para a reciclagem.
\end{tabular}

Nota. Fonte: elaborado pelos autores.

A população escolhida, jovens universitários, ocorreu devido ao fato das influências estudadas se mostrarem ainda mais interessantes quando se trata de um público jovem, porque, além de ser visto como o futuro consumidor, está em uma fase da vida em que ocorre uma diminuição do contato com seus pais e se deparam com uma atmosfera propícia ao aparecimento de novas questões e tarefas que exigem resolução (Sprinthall \& Collins, 2003), entre elas, a separação de materiais para a reciclagem.

No final do século XIX e início do século XX, as mudanças provocadas pela industrialização, tanto na estrutura familiar quanto na carreira e urbanização, contribuíram para o 'surgimento' da adolescência, considerada um período transitório entre a infância e a fase adulta (Sprinthall \& Collins, 2003). De maneira semelhante, vem ocorrendo com os universitários. A fase pode considerada um período no qual não são nem adolescentes nem adultos. São pessoas que permanecem na escola e fora do mercado de trabalho, com idade aproximadamente entre 17 e 21 anos de idade (Sprinthall \& Collins, 2003).

O estudo se caracterizou como pesquisa survey (Malhotra, 2006), dividida em duas etapas: uma exploratória e qualitativa e outra descritiva e quantitativa; são apresentadas a seguir.

\section{Pesquisa Qualitativa}

A pesquisa exploratória foi necessária, pois a maneira de mensurar alguns construtos ainda não estava especificada e outros precisavam ser adaptados à realidade brasileira (Malhotra, 2006). Assim, o objetivo desta fase foi auxiliar na elaboração do instrumento de coleta da etapa quantitativa.

$\mathrm{Na}$ etapa qualitativa, a amostra abrangeu 11 entrevistas em profundidade, sendo cinco especialistas e seis universitários. Desta maneira, entrevistaram-se diversas pessoas: uma pessoa de um órgão do governo (Secretaria do Meio Ambiente), uma pessoa de uma organização não governamental relacionada ao tema da reciclagem (AVINA), uma pessoa de um Instituto Tecnológico vinculado ao Estado (TecPar) e duas professoras, sendo uma de escola particular e uma de escola pública.

Quanto aos universitários, a idade era um pré-requisito no desenvolvimento da pesquisa, 17 a 21 anos. Além disso, os entrevistados foram selecionados tendo como base o gênero, 3 do gênero masculino e 3 do feminino, e o tipo de Universidade em que estudam, 3 de universidade privada e 3 de universidade pública.

As entrevistas foram transcritas e analisadas por meio da análise de conteúdo (Bardin, 2006). As entrevistas com especialistas foram realizadas com uma abordagem direta, não disfarçada (Malhotra, 2006). Nas entrevistas com estudantes, dois tipos de abordagens foram utilizados, tanto a direta, quanto a indireta (Malhotra, 2006). Assim, as técnicas projetivas se mostraram interessantes como 
estímulos dos entrevistados para abordar alguns dos construtos, sendo utilizada a interpretação de figuras, técnica que se baseia no Thematic Apperception Test [TAT] (Aaker, Kumar, \& Day, 2004).

\section{Pesquisa Quantitativa}

Nesta etapa, o objetivo era verificar as relações propostas pelo modelo. A amostra foi nãoprobabilística por conveniência (Malhotra, 2006), visto que se resumiu em contatar unidades de amostra que eram convenientes, uma turma de estudantes (Aaker et al., 2004). Primeiramente, o préteste foi aplicado com 10 estudantes de Administração. Os questionários desta fase serviram para melhorar o instrumento de coleta por meio das análises das respostas e sugestões especificadas pelos entrevistados. Estes não foram analisados estatisticamente, devido ao número coletado. Após os ajustes, foram aplicados 386 questionários; porém, após a verificação dos dados, 35 questionários foram tidos como inadequados e desconsiderados, totalizando para as análises 351 questionários válidos.

Os dados quantitativos obtidos foram tabulados e tratados com as análises estatísticas apropriadas. Foi utilizado o software estatístico Statistical Package for Social Science [SPSS] e o software AMOS. O software AMOS foi utilizado para realizar a análise de Modelagem de Equações estruturais (Hair, Babin, Money, \& Samouel, 2005) e foi útil para testar o modelo proposto. Esta análise foi utilizada por ser uma técnica multivariada que serve para estimar uma série de relações de dependência interrelacionadas simultaneamente (Hair et al., 2005) e foi útil para testar o modelo proposto.

Para preparar os dados para a análise do modelo, foram realizadas análises da média, curtose e assimetria. Além disso, foram submetidos à análise fatorial exploratória e confirmatória (Hair et al., 2005; Malhotra, 2006). Para preparar o construto comportamento de separação de materiais para a reciclagem, também foi utilizada a técnica Análise de Correspondentes Múltiplos [MCA]. Segundo Marchetti, Prado e Pires (1998), a MCA é uma técnica adequada ao tratamento de dados em que há a necessidade da composição de um escore ou nota para descrever um fenômeno com respostas múltiplas.

\section{RESULTADOS}

Este item esta dividido em duas partes, primeiro é apresentado o instrumento de coleta de dados da etapa quantitativa e na sequência como foi realizada a preparação dos dados. O segundo item traz a verificação do modelo proposto.

\section{Instrumento de Coleta e Preparação dos Dados}

Após a análise das entrevistas da etapa exploratória, somada a revisão teórica, o instrumento de coleta foi desenvolvido. A Tabela 2 ilustra como o instrumento de coleta foi estruturado. A maioria dos construtos foi mensurada por meio de uma questão que continha diversas afirmações para que o entrevistado concordasse ou não, por meio de uma escala de dez pontos. 
Tabela 2

\section{Evidências da Etapa Qualitativa e Instrumento de Coleta da Etapa Quantitativa}

\begin{tabular}{|c|c|c|c|c|}
\hline \multirow[t]{2}{*}{ Construto } & \multicolumn{2}{|c|}{ Evidências da Etapa Qualitativa } & \multicolumn{2}{|c|}{ Evidências da Etapa Quantitativa } \\
\hline & Especialista & Universitários & Estrutura da Pergunta & Escala Utilizada \\
\hline $\begin{array}{l}\text { Comportamento } \\
\text { de separação de } \\
\text { materiais para a } \\
\text { reciclagem }\end{array}$ & $\begin{array}{l}\text { - O comportamento de reciclagem esta } \\
\text { relacionado com a separação de } \\
\text { materiais para este processo. } \\
\text { - Este comportamento pode sofrer } \\
\text { alteração dependendo do local que o } \\
\text { jovem se encontra. Porém, o jovem que } \\
\text { apresenta este comportamento não fará } \\
\text { distinção de materiais, irá reciclar todos } \\
\text { os possíveis. }\end{array}$ & $\begin{array}{l}\text { - Opinaram que as perguntas } \\
\text { deveriam ser com exemplos de } \\
\text { materiais. } \\
\text { - Sugeriram que este } \\
\text { comportamento está relacionado } \\
\text { com o jovem pensar antes de jogar } \\
\text { algo no lixo e separá-lo para a } \\
\text { reciclagem quando for o caso. }\end{array}$ & $\begin{array}{l}\text { Abordava a frequência de separação de } \\
\text { dezenove tipos de materiais recicláveis. }\end{array}$ & $\begin{array}{l}\text { Escala de frequência de sete } \\
\text { pontos (menos de uma vez } \\
\text { por mês - todos os dias). }\end{array}$ \\
\hline $\begin{array}{l}\text { Conhecimento } \\
\text { Objetivo }\end{array}$ & $\begin{array}{l}\text { - Importância de conhecer o processo. } \\
\text { - Conforme surgem novas tecnologias, } \\
\text { materiais que antes não eram } \\
\text { recicláveis, passam a ser. } \\
\text { - Disponibilizaram o Material } \\
\text { informativo sobre programa de } \\
\text { reciclagem da prefeitura. }\end{array}$ & $\begin{array}{l}\text { - Mãe; } \\
\text { - Irmãos; } \\
\text { - Mídia - reportagens; } \\
\text { - Programa da Prefeitura (Família } \\
\text { Folha). }\end{array}$ & $\begin{array}{l}\text { - Foram listados } 14 \text { materiais para o } \\
\text { jovem assinalar quais eram recicláveis. } \\
\text { - Foram listados } 4 \text { locais que a } \\
\text { disposição e coleta de materiais podem } \\
\text { ocorrer para iniciar o processo de } \\
\text { reciclagem e o jovem deveria assinalar } \\
\text { quais opções estavam corretas. }\end{array}$ & $\begin{array}{l}\text { Apenas marcar as opções } \\
\text { corretas. }\end{array}$ \\
\hline $\begin{array}{l}\text { Conhecimento } \\
\text { Subjetivo }\end{array}$ & $\begin{array}{l}\text { Mesmas colocações apresentadas sobre } \\
\text { o Conhecimento Objetivo. }\end{array}$ & $\begin{array}{l}\text { Mesmas colocações apresentadas } \\
\text { sobre o Conhecimento Objetivo. }\end{array}$ & $\begin{array}{l}\text { - Um item questionava o quanto a } \\
\text { pessoa se sentia informada sobre os } \\
\text { materiais recicláveis. } \\
\text { - Um item questionava o quanto a } \\
\text { pessoa se sentia informada sobre os } \\
\text { locais que a coleta pode ser realizada. }\end{array}$ & $\begin{array}{l}\text { Escala de } 5 \text { pontos: muito } \\
\text { pouco - muito bom. }\end{array}$ \\
\hline Sentimentos & $\begin{array}{l}\text { Comentaram que os jovens também } \\
\text { podem apresentar sentimentos quando } \\
\text { não separam o material. }\end{array}$ & $\begin{array}{l}\text { Citaram quatro sentimentos (ex. } \\
\text { Satisfação) relacionados ao } \\
\text { momento que recicla e outros } \\
\text { quatro sentimentos quando não } \\
\text { recicla (ex. peso na consciência) }\end{array}$ & $\begin{array}{l}\text { - Foram listados } 12 \text { sentimentos e os } \\
\text { jovens assinalavam o grau de } \\
\text { concordância para as situações que } \\
\text { separava o material e para as situações } \\
\text { que não separa. }\end{array}$ & $\begin{array}{l}\text { Escala Likert de } 10 \text { pontos } \\
(1-\text { discordo totalmente até } \\
10 \text { - concordo. totalmente). }\end{array}$ \\
\hline
\end{tabular}

Continua 


\section{Tabela 2 (continuação)}

\begin{tabular}{|c|c|c|c|c|}
\hline \multirow[t]{2}{*}{ Construto } & \multicolumn{2}{|c|}{ Evidências da Etapa Qualitativa } & \multicolumn{2}{|c|}{ Evidências da Etapa Quantitativa } \\
\hline & Especialista & Universitários & Estrutura da Pergunta & Escala Utilizada \\
\hline Escola & $\begin{array}{l}\text { - Dois especialistas acreditam ser o } \\
\text { agente social que mais influencia. } \\
\text { - Um citou a importância dos trabalhos } \\
\text { práticos na escola. }\end{array}$ & $\begin{array}{l}\text { - Metade não se lembrava de um } \\
\text { trabalho específico sobre } \\
\text { reciclagem feito na escola. } \\
\text { - Metade lembrava-se de gincanas } \\
\text { ou trabalhos sobre o tema. }\end{array}$ & $\begin{array}{l}\text { - Foram listadas } 8 \text { afirmações sobre a } \\
\text { influência da escola, cada uma deveria } \\
\text { ser respondida para cada época de } \\
\text { ensino - Ensino Infantil, Ensino } \\
\text { Fundamental e Ensino Médio. } \\
\text { - Foram explorados temas como } \\
\text { trabalhos, gincanas e assuntos do meio } \\
\text { ambiente. }\end{array}$ & $\begin{array}{l}\text { Escala Likert de } 10 \text { pontos } \\
(1-\text { discordo totalmente até } \\
10 \text { - concordo totalmente }) .\end{array}$ \\
\hline Família & $\begin{array}{l}\text { - Destacaram a influência dos filhos na } \\
\text { família }\end{array}$ & $\begin{array}{l}\text { - Citaram pai, mãe e irmãos como } \\
\text { agentes de influência da família. } \\
\text { - Uma citou que a influência veio } \\
\text { da funcionária da casa para a } \\
\text { família. }\end{array}$ & $\begin{array}{l}\text { - Foram listadas } 10 \text { afirmações sobre a } \\
\text { influência da família, cada uma deveria } \\
\text { ser respondida para cada membro (pai, } \\
\text { mãe e irmão). } \\
\text { - Foram listados três itens que } \\
\text { abordavam a influência de maneira geral } \\
\text { e não em relação à um membro } \\
\text { específico. }\end{array}$ & $\begin{array}{l}\text { Escala likert de } 10 \text { pontos (1 } \\
\text { - discordo totalmente até } 10 \\
\text { - concordo totalmente). } \\
\text { Alternativa } 11 \text { (não se } \\
\text { aplica) para casos dos } \\
\text { respondentes que não tinham } \\
\text { irmãos. }\end{array}$ \\
\hline Mídia & $\begin{array}{l}\text { - A mídia é importante, pois influência } \\
\text { também os outros agentes sociais. } \\
\text { - A influência da mídia é mais para } \\
\text { informação do que para mudança de } \\
\text { comportamento. }\end{array}$ & $\begin{array}{l}\text { - A internet foi a mídia preferida e } \\
\text { mais utilizada por todos os jovens } \\
\text { entrevistados. } \\
\text { - A maioria lembrava-se de } \\
\text { assuntos sobre reciclagem na mídia. }\end{array}$ & $\begin{array}{l}\text { - Foram listadas } 5 \text { afirmações sobre a } \\
\text { influência da mídia, cada uma deveria } \\
\text { ser respondida para cada tipo de mídia: } \\
\text { TV, revista, rádio, internet e jornal } \\
\text { impresso. }\end{array}$ & $\begin{array}{l}\text { Escala Likert de } 10 \text { pontos ( } 1 \\
\text { - discordo totalmente até } 10 \\
\text { - concordo totalmente). }\end{array}$ \\
\hline Pares & $\begin{array}{l}\text {-Acreditam que dos quatro agentes é o } \\
\text { que menos influência. }\end{array}$ & $\begin{array}{l}\text { - Percebeu-se que este agente é um } \\
\text { dos que menos influenciou, com } \\
\text { base na percepção dos } \\
\text { entrevistados. } \\
\text { - Alguns costumam conversar com } \\
\text { seus amigos sobre o assunto, sendo } \\
\text { algumas vezes sobre o meio } \\
\text { ambiente no geral. }\end{array}$ & $\begin{array}{l}\text { - Foram listadas } 12 \text { afirmações sobre a } \\
\text { influência dos pares, cada uma deveria } \\
\text { ser respondida para amigos, colegas de } \\
\text { trabalho/estágio e namorado(a). }\end{array}$ & $\begin{array}{l}\text { Escala Likert de } 10 \text { pontos (1 } \\
\text { - discordo totalmente até } 10 \\
\text { - concordo totalmente). } \\
\begin{array}{lll}\text { Alternativa } 11 & \text { (não se } \\
\text { aplica) para } & \text { casos } & \text { dos } \\
\text { respondentes que não } & \text { nes } \\
\text { trabalhassem } & \text { ou não } \\
\text { namorassem. }\end{array}\end{array}$ \\
\hline
\end{tabular}

Nota. Fonte: elaborado pelos autores. 
Antes de apresentar os resultados, algumas considerações da caracterização da amostra são mostradas. Conforme foi destacado na metodologia, a idade entre 17 e 21 anos era um pré-requisito para o preenchimento do instrumento de coleta. A amostra apresentou um pouco mais da metade dos respondentes do sexo feminino (55\%) e, com base na classificação da ABA/NEP 2008, a maioria dos entrevistados foi enquadrada na classe social B1 (27\%), seguida da classe social A2 (25\%). Mais da metade estuda em Universidade Pública (68,4\%).

Para conduzir as análises, antes da verificação do modelo, foi realizada a preparação dos dados. Primeiramente, foi verificada a ocorrência de missing values. A opção 'Não se aplica', considerada um valor fora do limite da escala foi analisada como missing values também. Após a verificação foram excluídos os itens com mais de 10\% de missing values (Malhotra, 2006). Para os outros indicadores que apresentaram quantidade de missing inferiores a $10 \%$, a ação corretiva foi a substituição dos dados perdidos pelas médias respectivas de cada variável (Hair et al., 2005). Esta ação é considerada pelos autores como adequada por manter a consistência no cálculo das correlações, além de maximizar o número de casos do estudo. Na sequência, foi feita a inspeção das estatísticas descritivas univariadas e multivariadas das escalas, na qual a média, desvio padrão, curtose e assimetria foram analisadas para cada variável; sua análise mostrou que os valores foram aceitáveis.

Na preparação dos dados, os construtos conhecimento objetivo e comportamento de separação de materiais para a reciclagem tiveram um tratamento diferenciado dos demais. Em relação ao conhecimento objetivo, foi calculado um escore por meio de pesos dados aos materiais e locais abordados. As opções foram agrupadas como de conhecimento básico, intermediário e elevado, com base na entrevista com os especialistas e no julgamento dos pesquisadores.

Para analisar o comportamento de separação de materiais para a reciclagem foi utilizada a Análise de Correspondentes Múltiplos [MCA]. Este método se mostra interessante, pois pode basear-se tanto na intensidade quanto na variedade dos comportamentos de separação de materiais para a reciclagem (Marchetti et al., 1998). Com os ajustes necessários, passaram a ser considerados 16 dos 19 itens abordados no questionário. Por meio da Análise de Correspondentes Múltiplos [MCA], cada entrevistado passou a ter um escore de comportamento de separação de resíduos para a reciclagem.

Após estas análises, foi realizada a Análise Fatorial Exploratória e na sequência a análise fatorial confirmatória (Hair et al., 2005; Malhotra, 2006). A Análise fatorial exploratória foi utilizada para os seguintes construtos: Família, Escola, Mídia, Pares, Conhecimento Subjetivo e Sentimento. O principal objetivo de sua utilização foi manter a natureza e o caráter das variáveis originais, mas reduzir seu número para facilitar as próximas análises (Hair et al., 2005). Na análise fatorial exploratória foi realizada a medida Kaiser-Meyer-Olkin [KMO] e o Alfa de Cronbach, cujos resultados se mostraram adequados (Hair et al., 2005) e são apresentados no quadro 3.

$\mathrm{Na}$ análise fatorial confirmatória foi utilizado o software AMOS e avaliadas medidas de ajustamento absolutas e medidas comparativas de ajustamento. Os resultados foram: $\mathrm{X}^{2}=336,380 ; \mathrm{gl}=176 ; \mathrm{X}^{2} / \mathrm{gl}$ $=1,911 ; \mathrm{RMSEA}=0,051 ; \mathrm{NFI}=0,916 ; \mathrm{CFI}=0,958 ; \mathrm{e} \mathrm{IFI}=0,958 . \mathrm{O} \mathrm{X} / \mathrm{gl}$ deveria ser inferior a 5 ; o erro (RMSEA) inferior à 0,08 e as medidas de ajustamentos (NFI, CFI e IFI) superiores a 0,9 . Desta maneira, fica evidente que os índices da CFA encontram-se adequados e que os itens estão convergindo para as variáveis que constituem (Hair et al., 2005). Além disso, os valores da confiabilidade composta e da variância média extraída também estão de acordo com o especificado pela literatura, pois seus valores foram superiores a 0,7 e 0,5 respectivamente. Os resultados da análise discriminantes foram todos aceitáveis dentro das recomendações da literatura.

A Tabela 3 traz de maneira resumida os resultados da análise fatorial exploratória e da análise fatorial confirmatória. 
Tabela 3

Resumo Comparativo entre as AFE e AFC

\begin{tabular}{lcccc}
\cline { 3 - 5 } & \multicolumn{2}{c}{ Análise Fatorial Exploratória } & $\begin{array}{c}\text { Análise Fatorial } \\
\text { Confirmatória }\end{array}$ \\
\cline { 2 - 5 } & KMO & Dimensões & Alfa de Crombach & Dimensões \\
\hline Família & 0,792 & 6 dimensões & $0,990 / 0,884 / 0,865 /$ & 2 dimensões \\
& & & $0,860 / 0,855 / 0,791$ & \\
Escola & 0,822 & 5 dimensões & $0,916 / 0,880 / 0,832 /$ & Unidimensional (4 itens) \\
& & & $0,774 / 0,767$ & \\
Pares & 0,858 & 3 dimensões & $0,908 / 0,883 / 0,856$ & 2 dimensões \\
Mídia & 0,890 & 3 dimensões & $0,939 / 0,907 / 0,870$ & Unidimensional (2 itens) \\
Conhecimento & 0,500 & Unidimensional & 0,733 & Unidimensional (2 itens) \\
Subjetivo & & $(2$ itens) & & \\
Sentimentos & 0,829 & 3 dimensões & $0,862 / 0,855 / 0,884$ & Unidimensional (5 itens) \\
\hline
\end{tabular}

Nota. Fonte: elaborado pelos autores.

Destaca-se que os construtos Conhecimento Objetivo e Comportamento de Separação de Materiais para a Reciclagem não tiveram este tratamento, devido à maneira como foram mensurados e acabaram gerando escores.

\section{Análise do Modelo}

Para analisar o modelo foram verificados os índices de ajustamento e os coeficientes obtidos. Estes indicadores demonstram a significância por meio dos valores correspondentes ao t-value para cada caminho (path) utilizado no modelo. Os indicadores do modelo apresentaram os seguintes valores: $\mathrm{X}^{2}=284,443, \mathrm{gl}=166, \mathrm{X}^{2} / \mathrm{gl}=1,714, \mathrm{RMSEA}=0,045, \mathrm{NFI}=0,929, \mathrm{CFI}=0,969, \mathrm{IFI}=0,969$ e $\mathrm{RFI}=$ 0,910. Estes valores mostram um ajustamento adequado do modelo (Hair et al., 2005). A Tabela 4 mostra os resultados obtidos.

Tabela 4

\section{Resultados das Hipóteses do Modelo Proposto}

\begin{tabular}{lcccc}
\hline \multicolumn{1}{c}{ Relação Estrutural } & $\begin{array}{c}\text { Coef. } \\
\text { Padronizado }\end{array}$ & t-value & Hip. & $\begin{array}{c}\text { Status da } \\
\text { Hipótese }\end{array}$ \\
\hline Família $\rightarrow$ Comportamento de Reciclagem & 0,112 & $1,7 * * * *$ & H1a & Confirmada \\
Escola $\rightarrow$ Comportamento de Reciclagem & 0,031 & 0,551 & H1b & Não confirmada \\
Mídia $\rightarrow$ Comportamento de Reciclagem & 0,022 & 0,399 & H1c & Não confirmada \\
Pares $\rightarrow$ Comportamento de Reciclagem & 0,168 & $2,375^{* * *}$ & H1d & Confirmada \\
Família $\rightarrow$ Conhecimento Objetivo & 0,01 & 0,145 & H2a & Não confirmada \\
Escola Conhecimento Objetivo & 0,006 & 0,102 & H2b & Não confirmada \\
Mídia $\rightarrow$ Conhecimento Objetivo & 0,085 & 1,433 & H2c & Não confirmada \\
Pares $\rightarrow$ Conhecimento Objetivo & 0,042 & 0,581 & H2d & Não confirmada \\
Família $\rightarrow$ Conhecimento Subjetivo & 0,074 & 0,923 & H3a & Não confirmada \\
\hline
\end{tabular}

Continua 
Tabela 4 (continuação)

\begin{tabular}{|c|c|c|c|c|}
\hline Relação Estrutural & $\begin{array}{c}\text { Coef. } \\
\text { Padronizado }\end{array}$ & t-value & Hip. & $\begin{array}{l}\text { Status da } \\
\text { Hipótese }\end{array}$ \\
\hline Escola $\rightarrow$ Conhecimento Subjetivo & 0,006 & 0,096 & $\mathrm{H} 3 \mathrm{~b}$ & Não confirmada \\
\hline Mídia $\rightarrow$ Conhecimento Subjetivo & 0,021 & 0,325 & $\mathrm{H} 3 \mathrm{c}$ & Não confirmada \\
\hline Pares $\rightarrow$ Conhecimento Subjetivo & 0,134 & 1,504 & $\mathrm{H} 3 \mathrm{~d}$ & Não confirmada \\
\hline Família $\rightarrow$ Sentimento & 0,04 & 0,573 & $\mathrm{H} 4 \mathrm{a}$ & Não confirmada \\
\hline Escola $\rightarrow$ Sentimento & 0,172 & $2,877 * *$ & $\mathrm{H} 4 \mathrm{~b}$ & Confirmada \\
\hline Mídia $\rightarrow$ Sentimento & 0,102 & $1,71 * * * *$ & $\mathrm{H} 4 \mathrm{c}$ & Confirmada \\
\hline Pares $\rightarrow$ Sentimento & 0,154 & $2,078 * * *$ & $\mathrm{H} 4 \mathrm{~d}$ & Confirmada \\
\hline Conhecimento Objetivo $\rightarrow$ Comp. de Reciclagem & 0,031 & $1,981 * * *$ & H5 & Confirmada \\
\hline Conhecimento Subjetivo $\rightarrow$ Comp. de Reciclagem & $-0,093$ & $-1,629$ & H6 & Não confirmada \\
\hline Sentimento & 0,217 & 3,914 & $\mathrm{H} 7$ & Confirmada \\
\hline
\end{tabular}

Nota. Fonte: tratamento dos dados da pesquisa

* Resultados significativos a 0,$001 ; * *$ Hipótese confirmada a nível significante 0,$01 ; * *$ Hipótese confirmada a nível significante 0,05 ; ***Hipótese confirmada a nível significante 0,1 .

A primeira hipótese abordava a influência dos agentes de socialização no comportamento de separação de materiais para a reciclagem.

H1: Os agentes sociais afetam positivamente o comportamento de separação de materiais para a reciclagem.

Observa-se que ela foi confirmada parcialmente, pois dois dos agentes sociais mostraram que afetam o comportamento de separação de materiais para a reciclagem, o que é condizente com alguns achados sobre a influência dos agentes de socialização em outros tipos de comportamentos (Churchill \& Moschis, 1979; J. Moore et al., 2002; Moschis \& Churchill, 1978; Moschis \& Moore, 1978, 1979, 1982; R. Moore \& Stephens, 1975). Além destes estudos, Werner et al. (1995) também já haviam relatado a influência da família, vizinhos e escola.

Por meio da análise do modelo estrutural, verificou-se que a família afeta positivamente o comportamento de separação de materiais para a reciclagem, H1a $(\beta=0,112 ; p<0,1)$. Isso mostra a importância que esta instituição tem na formação dos jovens.

Em relação à escola, H1b, não foi encontrada uma influência direta desta no comportamento. Porém, os resultados de outras hipóteses mostram que esta influência pode ser indireta, ao influenciar o sentimento, que é considerado um antecedente do comportamento. Uma possível explicação é o fato de os jovens apresentarem menor contato com este agente no momento, visto que já estão na Universidade, o que dificulta a percepção desta influência.

Em relação à mídia, H1c, também não foi encontrada influência direta desta no comportamento. Porém, os resultados das hipóteses subsequentes mostram que esta influência pode ser indireta, pois a mídia afeta o sentimento, antecedente do comportamento.

Os pares, H1d, também afetam positivamente o comportamento de separação de materiais para a reciclagem $(\beta=0,168 ; p<0,05)$. Mais uma vez, o contato pessoal, que já havia sido constatado pela influência da família, se mostrou efetivo neste contexto.

As hipóteses que abordavam o conhecimento, $\mathbf{H} 2$ e H3, não se confirmaram para nenhum dos quatro agentes de socialização. Desta maneira, não foi encontrada uma relação da família, escola, pares e mídia com o conhecimento objetivo e subjetivo.

A relação teórica, base desta hipótese, estava apoiada em estudos que já comprovaram esta relação da família, escola, mídia e pares sobre outros tipos de conhecimento e não o conhecimento sobre 
reciclagem (Churchill \& Moschis, 1979; J. Moore et al., 2002; Moschis \& Churchill, 1978; Moschis \& Moore, 1978, 1979, 1982; R. Moore \& Stephens, 1975). Desta maneira, percebe-se que o contexto no qual foi realizada a pesquisa, reciclagem, estes agentes não comprovaram sua influência. Embora Luttropp e Johansson (2010) tenham destacado a importância da informação sobre reciclagem.

Uma possível explicação é o fato de a amostra abranger pessoas com níveis de conhecimento distintos, o que dificulta encontrar a relação. Desta maneira, como a amostra apresenta jovens com baixo conhecimento, a presença da influência dos agentes de socialização pode ter sido comprometida.

O sentimento foi o antecedente do comportamento que mostrou receber maior influência dos agentes sociais, de acordo com a hipótese H4:

H4: Os agentes sociais afetam positivamente o sentimento sobre separação de materiais para a reciclagem.

Dos quatro agentes de socialização estudados, apenas a família, H4a, não apareceu com uma relação positiva com o sentimento em relação à reciclagem. Uma possível explicação para a não confirmação da família no sentimento é a heterogeneidade da amostra. Para os demais agentes de socialização as sub-hipóteses foram confirmadas.

Em relação à H4b, pelas análises, observou-se que a escola $(\beta=0,172 ; \mathbf{p}<0,01)$ afeta positivamente o sentimento em relação à separação de materiais para a reciclagem. Com isto, evidencia-se que a escola auxilia o jovem a encontrar um propósito em separar os materiais para a reciclagem, ou seja, este agente estimula o jovem a apresentar sentimentos quando pratica esta ação.

A mídia, H4c, também foi confirmada como um agente de socialização que afeta positivamente o sentimento $(\beta=0,102 ; \mathrm{p}<0,1)$. Este agente de socialização também se mostrou importante por despertar sentimentos nos jovens em relação à separação de materiais para a reciclagem. Esta importância pode ser atribuída ao foco que as questões ambientais e atitudes de conservação, em que a reciclagem se enquadra, estão recebendo atualmente na mídia.

Por fim na H4d, os pares também se mostraram agentes de socialização importantes para o sentimento dos jovens em relação à reciclagem $(\beta=0,154 ; p<0,05)$. Uma possível explicação é o fato de os jovens terem seu grupo de amigos como referência, o qual pode incentivar e despertar sentimentos; sentimentos em relação à reciclagem podem ser um deles. Os pares foram os agentes de socialização que se mostraram mais influentes, pois afetam positivamente o comportamento e o sentimento.

Em relação aos antecedentes do comportamento de separação de materiais para a reciclagem, apenas a relação do conhecimento subjetivo com o comportamento não foi confirmada. A hipótese H5 abordava a relação do conhecimento objetivo com o comportamento de separação de materiais para a reciclagem, conforme o enunciado:

H5: O conhecimento objetivo afeta positivamente o comportamento de separação de materiais para a reciclagem.

O conhecimento objetivo, por meio das análises, afeta positivamente o comportamento de separação de materiais para a reciclagem $(\beta=0,031 ; p<0,05)$. Desta maneira, embora o conhecimento não tenha recebido influência dos agentes de socialização, ele é importante para que os jovens entrem em ação em relação à reciclagem. Com isto, conhecer os materiais e locais para a reciclagem é necessário para que o comportamento se manifeste.

Este resultado está de acordo com a base teórica utilizada (Brucks, 1985; Engel et al., 2000). Além de condizer com alguns trechos da literatura sobre reciclagem, como no estudo de Ebreo et al. (1999), no qual os respondentes que eram capazes de dar exemplos de produtos passíveis de reciclagem, participavam mais de programas de reciclagem. A hipótese H6 defendia a seguinte relação: 
H6: O conhecimento subjetivo afeta positivamente o comportamento de separação de materiais para a reciclagem.

Esta hipótese não foi confirmada e estava pautada nos dois tipos de conhecimento propostos por Brucks (1985) e ressaltado por Engel et al. (2000), os quais fazem referência à percepção dos consumidores sobre o nível de conhecimento que acreditam ter, o quanto e o que eles acham que sabem sobre a classe de produtos (Duhan et al., 1997; Park et al., 1994) e como isso afeta o comportamento dos indivíduos.

Uma das explicações para esta relação não ter sido comprovada é o fato de que na amostra há jovens que acreditam possuir um elevado conhecimento e outros que acreditam ter muito pouco conhecimento sobre reciclagem. A última hipótese propunha que:

H7: O sentimento atua positivamente sobre o comportamento de separação de materiais para a reciclagem.

O sentimento também atua positivamente no comportamento de separação de materiais para a reciclagem $(\beta=0,217 ; \mathrm{p}<0,001)$. Esta hipótese está de acordo com estudos que já haviam apontado alguns sentimentos presentes nas pessoas que reciclam, como as recompensas intrínsecas que Ebreo et al. (1999) cita dos estudos de Young sobre reciclagem; a satisfação é um dos sentimentos que os pesquisados afirmaram sentir por participarem de atividades de conservação (Ebreo et al., 1999). Com isto, destaca-se que para o jovem separar os materiais para a reciclagem não basta apenas conhecer, mas também é necessário sentir, ter um propósito nesta ação.

Então, após a demonstração dos resultados da pesquisa, serão apresentadas algumas considerações sobre o tema e as informações encontradas.

\section{DISCUSSÃO DOS RESULTADOS}

Os temas de que trata este artigo podem ser considerados atuais e ainda se encontram em fase exploratória. Portanto, as pesquisas promovem resultados que merecem maior carga de reflexões, discussões e atenção para futuros estudos.

Desta forma, a discussão dos resultados obtidos neste estudo foca três principais aspectos: (1) antecedentes do comportamento de separação de materiais para a reciclagem; (2) importância dos agentes de socialização para entender o comportamento de separação de materiais para a reciclagem; (3) peculiaridades de cada agente de socialização em relação ao comportamento de separação de materiais para a reciclagem.

O primeiro item proposto, as hipóteses $\mathrm{H} 5$ e $\mathrm{H} 7$ comprovaram que o conhecimento objetivo e o sentimento são importantes antecedentes do comportamento de reciclagem. No entanto, a não confirmação da hipótese H6 sobre o conhecimento objetivo corrobora o fato já alertado por Berger (1997) de que os antecedentes do comportamento de reciclagem estão em uma fase exploratória e resultados contraditórios podem surgir. Mesmo assim, esta situação pode ser considerada positiva, pois se alinha à afirmação de Valle et al. (2005), na qual os antecedentes são boa oportunidade de pesquisa. Além disso, o conhecimento já havia sido destacado como fator importante por Luttropp e Johansson (2010) na questão da reciclagem.

Além disso, a não confirmação da H6, por se tratar da percepção do jovem sobre seu conhecimento, levanta a reflexão: até que ponto os jovens realmente são conscientes do seu verdadeiro conhecimento sobre determinados assuntos? Até que ponto eles não supervalorizam seu conhecimento?

Esta questão também destaca a importância de tratar do conhecimento com a divisão proposta por Brucks (1985) e Engel et al. (2000), pois o verdadeiro conhecimento (conhecimento objetivo) muitas 
vezes não é o mesmo que os jovens julgam apresentar (conhecimento subjetivo). O conhecimento objetivo já se havia mostrado um antecedente do comportamento de separação de materiais para a reciclagem, como demonstra o estudo de Linn et al. (1994). O conhecimento subjetivo nos convida a refletir em como despertar o interesse do jovem a buscar mais informações sobre assuntos que ele julga conhecer bem, mas que essa situação não pode ser comprovada na realidade. Principalmente, por se tratar de um assunto em que novos conhecimentos são constantemente gerados, analisando, por exemplo, as tecnologias e novos processos que surgem para lidar com todos os tipos de resíduos gerados pela sociedade.

Ainda sobre o primeiro item, o sentimento como antecedente coincide com o estudo de Hopper e Nielsen (1991): os mais propensos a agir são os que acreditam na diferença que suas ações podem provocar; e com o estudo de Carrus et al. (2008) sobre a antecipação de emoções negativas como antecedente da intenção de comportamento ambiental. Assim, surge a reflexão sobre a abordagem a respeito da reciclagem, quando se trata de programas ou mesmo informações para conscientizar os jovens e torná-los cada vez mais engajados em ações que podem ir além de apenas do simples binômio consumir e descartar. O sentimento como antecedente também coloca maior enfoque na sensibilização, visto que foi por meio dele que ocorreu a maioria das influências dos agentes de socialização.

O segundo item, os agentes de socialização mostraram que um novo enfoque pode ser dado às pesquisas desta natureza, visto que um baixo número de estudos foi encontrado sobre a influência da família, da mídia, da escola e dos pares na adoção de comportamentos ligados à reciclagem (Gronhoj \& Thogersen, 2009; Lyons \& Breakwell, 1994; Manieri et al., 1997; Werner et al., 1995).

As influências sociais já haviam sido estudadas por um grupo de autores que as testaram em diversos contextos, encontrando diferentes tipos de resultados (Churchill \& Moschis, 1979; J. Moore et al., 2002; Moschis \& Churchill, 1978; Moschis \& Moore, 1978, 1979, 1982; R. Moore \& Stephens, 1975). Ao relacionar o comportamento de reciclagem com as influências sociais, este estudo realiza uma pequena contribuição teórico-metodológica na área de interseção entre os campos de comportamento do consumidor e de preservação ambiental, demonstrando alguns aspectos que influenciam positivamente a reciclagem e outros que precisam ser mais estudados para que se compreenda o modo como eles exercem suas influências.

Por fim, o terceiro item discute como cada agente de socialização apresentou importância, ao influenciar os jovens para este comportamento. Embora os resultados possam não surpreender, estes passam a ser valiosos, por documentar e comprovar empiricamente as relações propostas. Justificativa também utilizada por Gronhoj e Thogersen (2009) quando estudaram pais e filhos em relação ao comportamento de compra de produtos ambientalmente favoráveis, uso de eletricidade e maneira como lidam com o lixo.

A literatura já havia apontado a importância desses agentes para outros comportamentos; porém, dentro do contexto da reciclagem, é interessante levar em consideração o peso que a família, os pares, a escola e a mídia apresentam.

O primeiro ponto é que o contato pessoal ainda representa maior peso na influência direta do comportamento, conforme ficou demonstrado pela confirmação das hipóteses H1a e H1d. Ou seja, as pessoas se mostraram mais eficazes na influência do comportamento do que as organizações (mídia e escola). Porém, de maneira indireta, a escola, a mídia e os pares agem no sentimento, considerado como antecedente que influencia o comportamento. Desta maneira, estes agentes se mostram importantes agentes de sensibilização dos jovens.

O agente de socialização pares foi o único que apareceu duas vezes: influencia o comportamento e o sentimento. Este resultado está alinhado à proposição de Sprinthall e Collins (2003), em que os jovens universitários estão em fase em que diminuem o contato com seus pais, além de se depararem com novos assuntos e tarefas que exigem resolução. Focar nos agentes de socialização também contribui para entender todas as relações que ocorrem no meio que está sendo pesquisado. Este aspecto pode ser 
levado em consideração na maioria dos estudos que procuram explorar outros tipos de comportamentos apresentados pelos consumidores.

\section{CONSIDERAÇÕES FINAIS}

Com o objetivo de contribuir para os estudos de uma etapa do processo decisório do consumidor ainda pouco explorada nacionalmente, este estudo buscou nas teorias de socialização do consumidor a maneira de entender o comportamento de separação de materiais para a reciclagem na perspectiva dos jovens universitários. As influências sociais já haviam sido estudadas por um grupo de autores que as testaram em diversos contextos. Porém, a colaboração deste estudo foi relaciona-las com o comportamento de separação de materiais para a reciclagem.

Desta maneira, nesta seção procura-se abordar os tópicos principais: contribuições teóricas do estudo, implicações práticas, limitações e sugestões de futuras pesquisas.

Como principal contribuição teórica, esta pesquisa auxilia no entendimento de um tema que ainda foi pouco explorado, principalmente no âmbito da pesquisa científica nacional. Já havia sido alertado que este assunto ainda está em fase exploratória (Berger, 1997). Entender os antecedentes deste comportamento oferece diferentes oportunidades de pesquisa (Valle et al., 2005).

Em relação às implicações práticas, três setores que podem ser beneficiados com o maior entendimento das influências no comportamento de separação de materiais para a reciclagem dos jovens são: empresas, governo e meio ambiente. Além disso, é interessante notar o peso que cada agente teve de acordo com os resultados encontrados. Com estas considerações, as famílias e os jovens, bem como os proprietários de meios de comunicação e de escolas percebem o peso que representam para influenciar determinados jovens em relação ao assunto da reciclagem. Assim, a partir dos resultados confirmados na pesquisa, eles precisam considerar mais essa temática no cotidiano de suas atividades.

Como em toda pesquisa, as limitações também estão presentes. A amostra utilizada, caracterizada como não-probabilística (Malhotra, 2006), embora proporcione boas estimativas das características da população, pode não permitir uma avaliação objetiva da precisão dos resultados amostrais. Sendo assim, os resultados obtidos não poderão ser generalizados para toda a população com o mesmo perfil amostral. A população escolhida se mostrou interessante para este estudo com base na literatura utilizada. Porém, compromete a generalização dos resultados para o universo de consumidores que poderiam ser enquadrados nesta categoria.

Por fim, o objetivo principal de um estudo desta natureza é continuar contribuindo para a produção de conhecimento. Assim, seguem algumas considerações sobre possibilidades de futuras pesquisas pautadas nos resultados obtidos. Sugere-se que os trabalhos sigam o caminho contrário do proposto neste estudo, ou seja, verifiquem a influência dos jovens universitários no comportamento de seus pais e pares. Outra sugestão é que os estudos futuros englobem na última etapa do processo decisório do consumidor, além da reciclagem, outros comportamentos que podem ser apresentados pelos consumidores, como, por exemplo, a reutilização e a redução de materiais que seriam descartados.

\section{Artigo recebido em 17.09.2009. Aprovado em 05.07.2010.}

\section{REFERÊNCIAS BIBLIOGRÁFICAS}

Aaker, D., Kumar, V., \& Day, G. S. (2004). Pesquisa de marketing. São Paulo: Atlas. 
Ahava, A., \& Palojoki, P. (2004). Adolescent consumers: reaching them, border crossings and pedagogical challenges. International Journal of Consumer Studies, 28(4), 371-378.

Alba, J. W., \& Hutchinson, J. W. (1987). Dimensions of consumer expertise. Journal of Consumer Research, 13(4), 411-54.

Bardin, L. (2006). Análise de conteúdo (4a ed.). Lisboa: Edições 70.

Bekin, C., Carrigan, M., \& Szmigin, I. (2007). Caring for the community: an exploratory comparison of waste reduction behavior by British and Brazilian consumers. International Journal of Sociology and Social Policy, 27(5-6), 221-233.

Benn, J. (2004). Consumer education between consumership and citiezenship: experiences from studies of young people. International Journal of Consumer Studies, 28(2), 108-116.

Berger, I. (1997). The demographics of recycling and the structure of environmental behavior. Environment and Behavior, 29(4), 515-531.

Bettman, J., \& Park, C. (1980). Effects of prior knowledge and experience and phase of the choice process on consumer decision process: a protocol analysis. Journal of Consumer Research, 7(3), 234-248.

Binder, C., \& Mosler, H. (2007). Waste-resource flows of short-lived goods in households of Santiago de Cuba. Resources, Conservations and Recycling, 51(2), 265-283.

Brucks, M. (1985). The effects of product class knowledge on information search behavior. Journal of Consumer Research, 12(1), 1-16.

Busch, A., Smith, R., \& Martin, C. (1999). The influence of consumer socialization variables on attitude toward advertising: a comaprison of African-Americans Caucasians. Journal of Advertising, 28(3), 13-24.

Carrus, G., Passafaro, P., \& Bonnes, M. (2008). Emotions, habits and rational choices in ecological behavirous: the case of recycling and use public transportation. Journal of Environmental Psychology, 28(1), 51-62.

Churchill, G., \& Moschis, G. (1979). Television and Interpersonal influences on adolescent consumer learning. Journal of Consumer Research, 6(1), 23-35.

Compromisso Empresarial para a Reciclagem. (2008). A evolução da coleta seletiva e reciclagem de resíduos sólidos urbanos no Brasil. Recuperado em 2 maio, 2008, de http://www.cempre.org.br/imprensa.php?codeps=fHx 8fHx8fHx8fHx8fDE1

Corral-Verdugo, V. (1997). Dual 'realities' of conservation behavior: self-reports vs observations of re-use and recycling behavior. Journal of Environmental Psychology, 17(2), 135-145.

Cotte, J., \& Wood, S. (2004). Families and innovative consumer behavior: a triadic analysis of sibling and parental influence. Journal of Consumer Research, 31(1), 78-86.

Daneshvary, N., Daneshvary, R., \& Schwer, R. (1998). Solid-waste recycling behavior and support for cuberside textile recycling. Environment and Behavior, 30(2), 144-161.

Demajorovic, J. (1995). Da política tradicional de tratamento do lixo à política de gestão de resíduos sólidos - as novas prioridades. Revista de Administração de Empresas, 35(3), 88-93.

Duhan, D., Johnson, S., Wilcox, J., \& Harrell, G. (1997) Influences on consumer use of word-ofmouth recommendations sources. Journal of the Academy of Marketing Science, 25(4), 283295. 
Ebreo, A., Hershey, J., \& Vining, J. (1999). Reducing solid waste: linking recycling to environmentally responsible consumerism. Environment and Behavior, 31(1), 107-135.

Ekvall, T. (1999). Key methodological issues for life cycle inventory analysis of paper recycling. Journal of Cleaner Production, 7(4), 281-294.

Engel, J., Blackwell, R., \& Miniard, P. (2000). Comportamento do consumidor (8a ed.). Rio de Janeiro: LTC.

Frijda, N., Manstead, A., \& Bem, S. (2000). The influence of emotions on beliefs. In N. Frijda, A. Manstead, \& S. Bem (Eds.), Emotions and beliefs - how feelings influence thoughts (pp. 1-9). Cambridge: Cambridge University Press.

Frijda, N., Mesquita, B., Sonnemans, J., \& Goozen, S. van (1991). The duration of affective phenomena of emotions, sentiments and passions. In K. T. Strongman (Coord.), International review of studies on emotion (Vol. 1, pp. 187-225). Inglaterra: Wiley.

Gronhoj, A., \& Thogersen, J. (2009). Like father, like son? Intergenerational transmission of values, attitudes, and behaviors in the environmental domain. Journal of Environmental Psychology, 29(4), 414-421.

Hair, J., Jr., Babin, B., Money, A., \& Samouel, P. (2005). Fundamentos de métodos de pesquisa em administração. Porto Alegre: Bookman.

Heckler, S. (1994). The role of memory in understanding and encouraging recycling behavior. Psychology \& Marketing, 11(4), 375-392.

Hopper, J. R., \& Nielsen, J. M. (1991). Recycling as altruistic behavior: normative and behavioral strategies to explain participation in community recycling program. Environment and Behavior, 23(2), 195-220.

Instituto Akatu Pelo Consumo Consciente. (2004). Descobrindo o consumidor consciente (Pesquisa no. 3). São Paulo, SP: Autor.

Johansson, J., \& Luttropp, C. (2009). Material hygiene: improving recycling of WEEE demonstrated on dishwashers. Journal of Cleaner Production, 17(1), 26-35.

John, D. (1999). Consumer socialization of children: a retrospective look at twenty-five years of Research. Journal of Consumer Research, 26(3), 183-213.

Kurz, T., Linden, M., \& Sheehy, N. (2007). Attitudinal and community influences on participation in new cuberside recycling initiatives in northern Ireland. Environment and Behavior, 39(3), 367391.

Lages, N. A., Vargas, A., Neto (2002, setembro). Mensurando a consciência ecológica do consumidor: um estudo realizado na cidade de Porto Alegre. Anais do Encontro Nacional da Associação Nacional de Pós-Graduação e Pesquisa em Administração, Salvador, BA, Brasil, 26.

Linn, N., Vining, J., \& Feeley, P. A. (1994). Toward a sustainable society: waste minimization through environmentally conscious consuming. Journal of Applied Social Psychology, 24(17), $1550-1572$.

Luttropp, C., \& Johansson, J. (2010). Improved recycling with life cycle information tagged to the product. Journal of Cleaner Production, 18(4), 346-354.

Lyons, E., Breakwell, G. M. (1994). Factors predicting environmental concern and indifference in 13to 16-year-olds. Environment and Behavior, 26(2), 223-238. 
Malhotra, N. (2006). Pesquisa de marketing: uma orientação aplicada (4a ed.). Bookman: Porto Alegre.

Manieri, T., Barnett, E., Valdero, T., Unipan, J., \& Oskamp, S. (1997). Green buying the influence of environmental concern on consumer behavior. The Journal of Social Psychology, 137(2), 189204.

Marchetti, R., Prado, P., \& Pires, P. (1998, setembro). Análise de correspondentes múltiplos aplicada à ordenação de dados qualitativos. Anais do Encontro Nacional da Associação Nacional de PósGraduação e Pesquisa em Administração, Foz do Iguaçu, PR, Brasil, 22.

McDonald, S., \& Ball, R. (1998). Public participation in plastics recycling schemes. Resources, Conservation and Recycling, 22(3-4), 123-141.

Moore, J., Raymond, M., Mittelstaedt, J., \& Tanner J. (2002). Age and consumer socialization agent influences on adolescents' sexual knowledge, attitudes, and behavior: implications for social marketing initiatives and public policy. Journal of Public Policy \& Marketing, 21(1), 37-52.

Moore, R., \& Stephens, L. (1975). Some communication and demographic determinants of adolescent consumer learning. Journal of Consumer Research, 2(2), 80-95.

Moore-Shay, E., \& Berchmans, B. (1996). The role of the family in the development of shared consumption values: an intergenerational study. Advances in Consumer Research, 23, 484-490.

Moschis, G., \& Churchill, G. (1978). Consumer socialization: a theoretical and empirical analysis. Journal of Marketing Research, 15(4), 599-609.

Moschis, G., \& Moore, R. (1978). An analysis of the acquisition of some consumer competencies among adolescents. The Journal of Consumer Affairs, 12(2), 277-298.

Moschis, G., \& Moore, R. (1979). Decision making among the young: a socialization perspective. Journal of Consumer Research, 6(2), 101-131.

Moschis, G., \& Moore, R. (1982). A longitudinal study of television advertising effects. Journal of Consumer Research, 9(3), 279-295.

Newcombe, N. (1999). Desenvolvimento infantil: abordagem de Mussen (8a ed.). Porto Alegre: Artes Médicas Sul.

Park, C., Mothersbaug, D., \& Feick, L. (1994). Consumer knowledge assessment. Journal of Consumer Research, 21(1), 71-82.

Ritson, M., \& Elliot, R. (1999). The social uses of advertising: an ethnographic study of adolescent advertising audiences. Journal of Consumer Research, 26(3), 260-277.

Romeiro, M. (2006). Um estudo sobre o comportamento do consumidor ambientalmente favorável: uma verificação no ABC paulista. Tese de doutorado, Universidade de São Paulo, São Paulo, SP, Brasil.

Schultz, P., Oskamo, S., \& Manieri, T. (1995). Who recycles and when? A review of personal and situational factors. Journal of Environmental Psychology, 15(2), 105-121.

Seacat, J. D., \& Northrup, D. (in press). An information-motivation-behavioral skills assessment of curbside recycling behavior. Journal of Environmental Psychology.

Shrum, L., Lowrey, T., \& McCarty, J. (1994). Recycling as a marketing problem: a framework for strategy development. Psychology \& Marketing, 11(4), 393-416. 
Shrum, L., O'Guinn, T., Semenik, R., \& Faber, R. (1991). Processes and effects in the construction of normative consumer beliefs: the role of television. Advances in Consumer Research, 18, 755763.

Sidique, S., Lupi, F., \& Joshi, S. (2010). The effects of behavior and attitudes on drop-off recycling activities. Resources, Conservation and Recycling, 54(3), 163-170.

Solomon, M. (2002). O comportamento do consumidor: comprando, possuindo e sendo (5a ed.). Porto Alegre: Bookman.

Sprinthall, N., \& Collins, W. (2003). Psicologia do adolescente: uma abordagem desenvolvimentista (3a ed.). Lisboa: Fundação Calouste Gulbenkian.

Suttibak, S., \& Nitivattananon, V. (2008). Assessment of factors influencing the performance of solid waste recycling programs. Resources, Conservations and Recycling, 53(1-2), 45-56.

Valle, P., Rebelo, E., Reis, E., \& Menezes, J. (2005). Combining behavioral theories to predict recycling involvement. Environment and Behavior, 37(3), 364-396.

Vining, J., \& Ebreo, A. (2002). Emerging theoretical and methodological perspectives on conservation behavior. In R. B. Bechtel \& A. Churchman (Eds.), Handbook of environmental psychology (pp. 541-558). New York: John Wiley.

Werner, C., \& Makela, E. (1998). Motivations and behaviors that support recycling. Journal of Environmental Psychology, 18(4), 373-386.

Werner, C., Sansone, C., \& Brown, B. (2008). Guided group discussion and attitude change: the roles of normative and informational influence. Journal of Environmental Psychology, 28(1), 27-41.

Werner, C. M., Turner, J., Shipman, K., Twitchell, F. S., Dickson, B. R., Bruschke, G. V., \& Bismarck, W. B. von (1995). Commitment, behavior, and attitude change: an analysis of voluntary recycling. Journal of Environmental Psychology, 15(3), 197-208. 